\title{
Scanning proximal microscopy study of the thin layers of silicon carbide- aluminum nitride solid solution manufactured by fast sublimation epitaxy
}

\author{
D. Dallaeva ${ }^{1}$, E. Korostylev ${ }^{2}$, B. Bilalov ${ }^{3}$ and P. Tománek ${ }^{1}$ \\ ${ }^{1}$ Brno University of Technology, Faculty of Electrical Engineering and Communication, Physics Department, \\ Technická 8, 61600 Brno, Czech Republic \\ ${ }^{2}$ Moscow Institute of Physics and Technology, 141700 Dolgoprudnyj, Russian Federation \\ ${ }^{3}$ Dagestan State University, Physics Department, 367025 Machachkala, Russian Federation
}

\begin{abstract}
The objective of the study is a growth of $\mathrm{SiC} /(\mathrm{SiC})_{1-\mathrm{x}}(\mathrm{AlN})_{\mathrm{x}}$ structures by fast sublimation epitaxy of the polycrystalline source of $(\mathrm{SiC})_{1-\mathrm{x}}(\mathrm{AlN})_{\mathrm{x}}$ and their characterisation by proximal scanning electron microscopy and atomic force microscopy. For that purpose optimal conditions of sublimation process have been defined. Manufactured structures could be used as substrates for wide-band-gap semiconductor devices on the basis of nitrides, including gallium nitride, aluminum nitride and their alloys, as well as for the production of transistors with high mobility of electrons and also for creation of blue and ultraviolet light emitters (light-emitted diodes and laser diodes). The result of analysis shows that increasing of the growth temperature up to $2300 \mathrm{~K}$ allows carry out sublimation epitaxy of thin layers of aluminum nitride and its solid solution.
\end{abstract}

\section{Introduction}

Wide-band-gap III-nitrides are undoubtedly a remarkable family of semiconductors. Unlike their semiconductor cousins, high-quality films of this material can be grown on almost any substrate - sapphire, silicon and even glass [1]. There are three options for native substrates: aluminum nitride $(\mathrm{AlN})$, gallium nitride $(\mathrm{GaN})$ and indium nitride $(\mathrm{InN})$ [2-4]. To date, no one has produced bulk crystal InN; $\mathrm{GaN}$ has been grown from solution at high pressure; and AlN has been produced using relatively straightforward physical vapor transport (sublimation) [5].

Silicon carbide $(\mathrm{SiC})$ and aluminum nitride (AIN) are recognized as excellent materials for optical systems of extreme conditions of exploitation and have attracted increasing interest for microelectronics and optoelectronics $[6,7]$.

Another strength of AIN is that it is the most promising universal substrate for epitaxy of a wide variety of nitride devices, including LEDs, lasers, RF and surface acoustic wave (SAW) devices. Of all the III-nitrides, it has the largest bandgap $(6,2 \mathrm{eV})$, highest thermal conductivity, breakdown electric field and SAW velocity, and the smallest a-lattice parameter. [8].

Therefore these materials are promising for design of hightemperature, high-power, microwave and optoelectronics devices because of their physical stability to external influences (thermal, chemical, radiation). [4, 9]. Silicon carbide is used for optical mirrors for the entire frequency range because it offers many advantages over other commonly used glasses and metals $[10,11]$. There is also a significant attention for use of silicon based alloys [12]. These materials are ideally suited for devises of extreme application conditions where silicon-based semiconductor electronics can not operate [13]. As it noted in [14] "there is a worldwide effort for the development of nitride electronics for high-power/temperature radio-frequency applications". Compositions of SiC-AlN system differ from the other traditional semiconductor material by stability of properties $[15,16]$. For these reasons the investigation of formation mechanisms of wide-band-gap semiconductor solid solutions on the basis of $\mathrm{SiC}$, and study of electrical, optical and mechanical properties, structure and morphology in dependence of obtaining conditions, are of larger demand.

Solid solution formation in SiC-AIN system with welldefined composition and consequently with expected physico-chemical and mechanical properties is possible on the basis of ultimate and detailed investigation of solid solution components interaction type and determination of connection between composition and properties. Furthermore, processes of formation are of theoretical interest for getting better insights about growth features of heterovalent solid solutions, which is still insufficiently known problem [17, 18]. Diferences in crystall lattice parameters make a lot of difficulties in formation of $\mathrm{SiC} / \mathrm{AlN}$ structures.

This is an Open Access article distributed under the terms of the Creative Commons Attribution License 2.0, which permits unrestricted use, distribution, and reproduction in any medium, provided the original work is properly cited. 


\section{Experimental procedures}

The test objects are $(\mathrm{SiC})_{1-\mathrm{x}}(\mathrm{AlN})_{\mathrm{x}}$ and $\mathrm{AlN}$ thin films deposited on the silicon carbide substrate. They were manufactured by fast sublimation epitaxy of polycrystalline source $(\mathrm{SiC})_{1-\mathrm{x}}(\mathrm{AlN})_{\mathrm{x}}$ with $\mathrm{x}=0.25$ and $\mathrm{x}=1$ at $\mathrm{T}=2100$ $\mathrm{K}, 2200 \mathrm{~K}$ and $2300 \mathrm{~K}$. The process of sublimation took place in nitrogen atmosphere at barometric pressure.

Morphology study and qualitative chemical analysis were made in order to find the growth optimal conditions of epitaxial layers of solid solution on the basis of $\mathrm{SiC}$ and AlN. The experimental results were obtained with FEI Quanta 200 and Quanta 200 3D scanning electron microscopes. Step etching by focused ion beam was used for study of structure and changing of chemical composition in depth. Current strength of the beam changed from 20pA up to $20 \mathrm{nA}$ and the accelerating potential from 1 up to $20 \mathrm{kV}$. The indication of beam current variation was used for control of interface crossing from epilayer down to substrate since it changes in dependence of material nature.

\section{Experimental results}

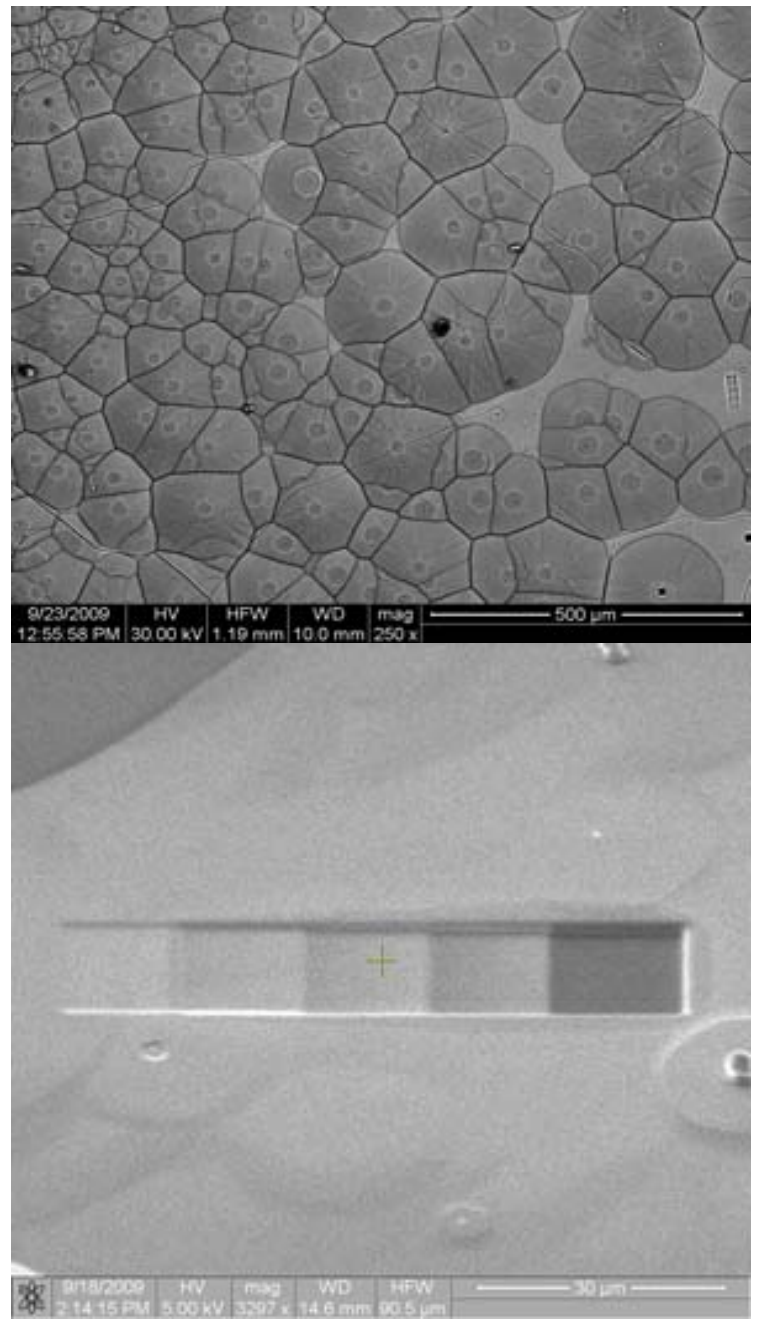

Fig.1. Epitaxial layer of $\mathrm{SiC}_{0.75} \mathrm{AlN}_{0.25}$ solid solution.

Figures 1 and 2 show the presence of typical hexagonal structure of the formatted layer $\mathrm{SiC}_{0.75} \mathrm{AlN}_{0.25}$ and there are components of solid solution on the surface

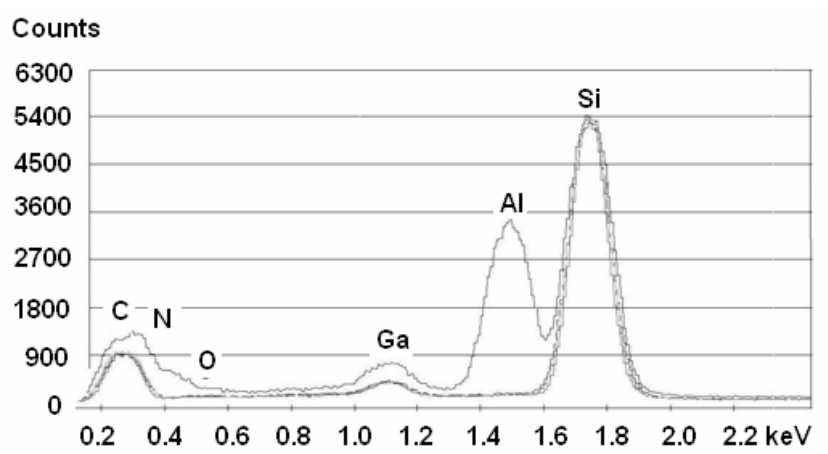

Fig. 2. Spectrum of chemical composition on different steps of etching of $\mathrm{SiC}_{0.75} \mathrm{AlN}_{0.25}$ solid solution epilayer

The same sample was studied by semi-contact atomic force microscopy (AFM), where we can observe the typical $120^{\circ}$ angles of the island sides as shown in figure 3 .

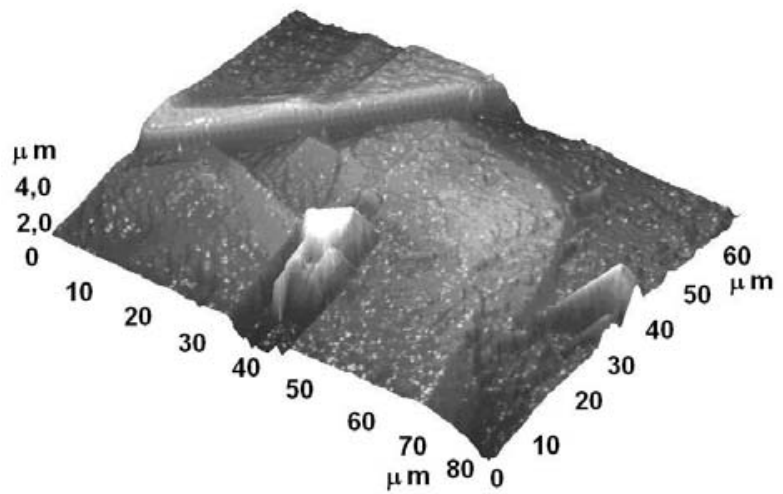

Fig.3. AFM image of the surface of layer of $\mathrm{SiC}_{0.75} \mathrm{AlN}_{0.25}$ solid solution (average roughness is $515.271 \mathrm{~nm}$ )

The presence of defects could be connected with imperfections of substrate surface (figure 4) and by this reason it is necessary to make careful preliminary preparation of the used substrate.

For AlN substrate production, crystals are separated from seed holders and the head cropped off, before being ground to a 2 -inch diameter and oriented by X-ray. Both major and minor US-convention flats are ground into the crystal. The round crystal is mounted to a slicing fixture and the mis-orientation angle of the substrates is fixed with $\mathrm{X}$-rays, before a multi-wire diamond saw slices the crystal into wafers. The sliced wafers are lapped as needed and then subjected to chemical mechanical polishing (CMP). Finally, the wafer is cleaned and packaged in a nitrogen atmosphere.

We have developed our own CMP final polishing for the production of seed substrates; however, final polishing of the AlN substrates can be made by Novasic (France) on request. Novasic has established a unique, industry recognized polishing capability for hard materials such as sapphire, SiC and AlN.

Characterization data, such X-ray diffraction and atomic force microscopy (AFM) measurements, is typically collected on the wafers after cleaning. A good assessment of the wafer production process is revealed by the quality of the epitaxy. Mapping of the surface topography with an 
AFM reveals the absence of scratches in the epilayer, attesting to the quality of the CMP.

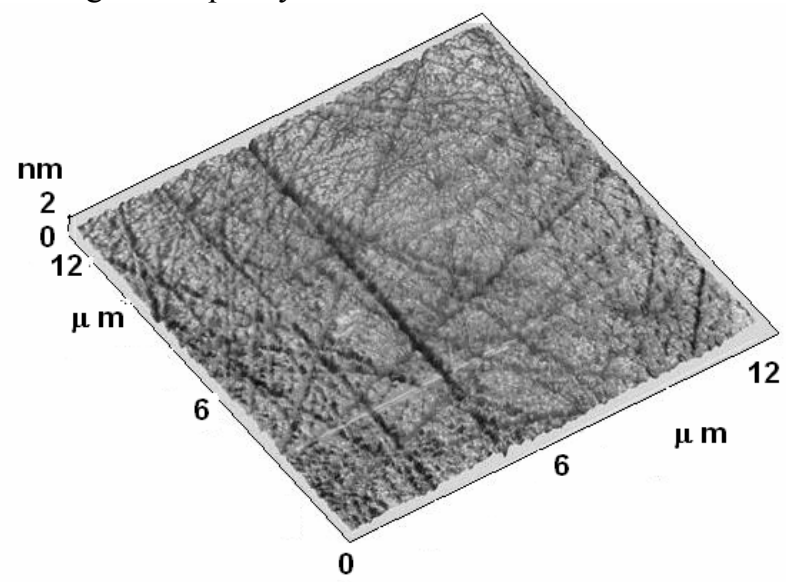

Fig.4. AFM image of the substrate surface of silicon carbide. (Ten points high is $20.5191 \mathrm{~nm}$ )

Sample with source of pure aluminum nitride $(\mathrm{x}=1)$ was also obtained by sublimation epitaxy. Morphology (figure 5) and chemical composition (figure 6) show the presence of AlN.

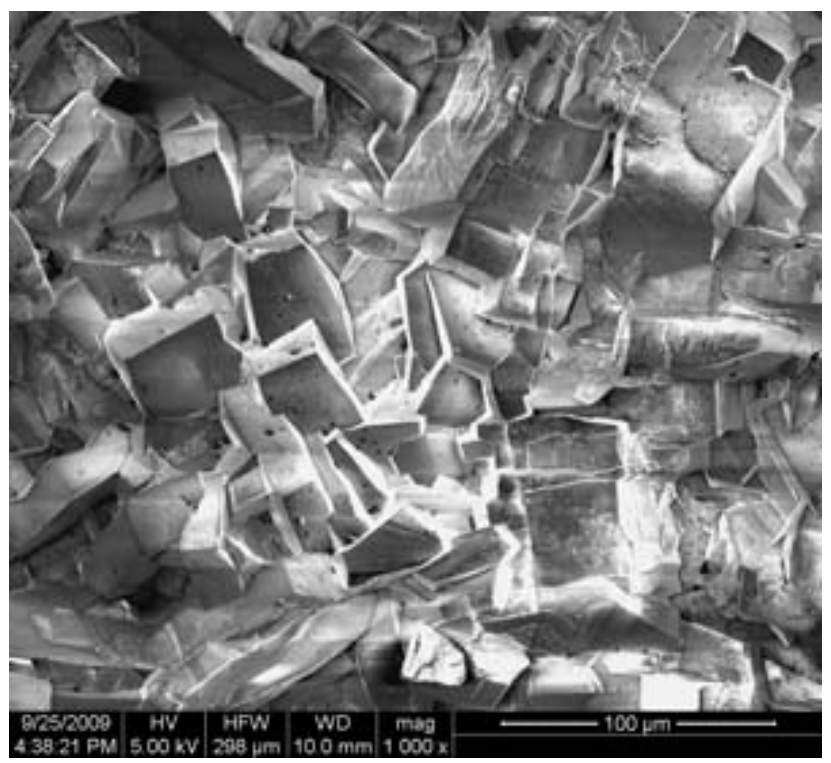

Fig.5. Epitaxial layer of aluminium nitride obtained at $\mathrm{T}=2300 \mathrm{~K}$

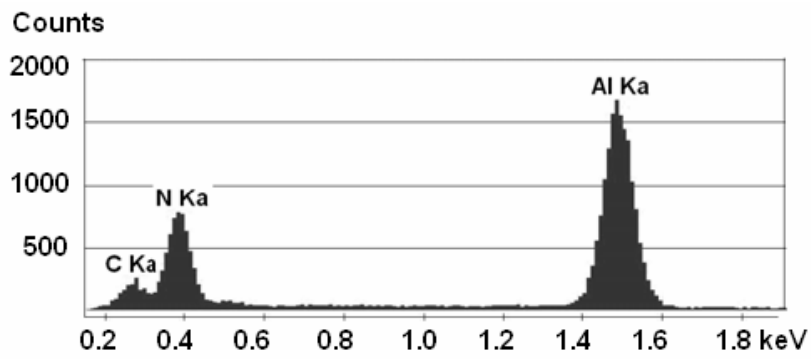

Fig. 6. Component analysis of the aluminium nitride epilayer obtained at $\mathrm{T}=2300 \mathrm{~K}$ Study of the sample obtained at $2200 \mathrm{~K}$ shows that the $\mathrm{K}$ allows carry out sublimation epitaxy of thin layers of layer has a certain structure (figure 7) but component aluminum nitride and its solid solution. analysis shows absence of the aluminum in different etching layers (figure 8).

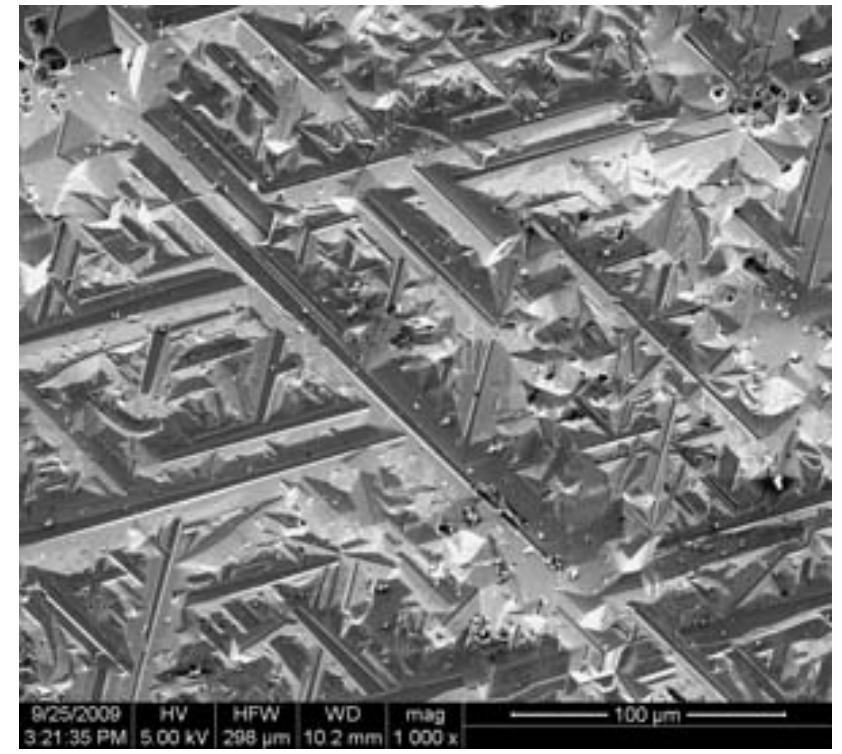

Fig.7. Epitaxial layer of aluminium nitride obtained at $\mathrm{T}=2200 \mathrm{~K}$

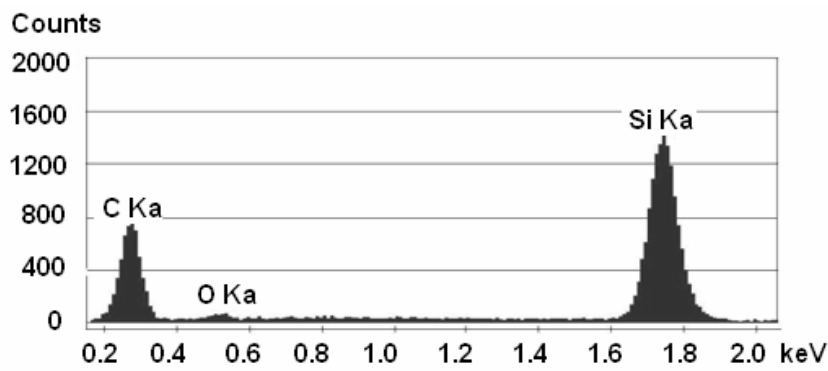

Fig. 8. Component analysis of the aluminium nitride epilayer obtained at $\mathrm{T}=2200 \mathrm{~K}$

Data of the sample obtained at $2100 \mathrm{~K}$ show that the epilayer is not appears or it was previously etched in hydrofluoric acid (figure 9). The sample has a porous surface and aluminum is only insight pores down to $2 \mu \mathrm{m}$, but on the other part of surface it is missing.

\section{Conclusions}

The results of the study are structures of $\mathrm{SiC} /(\mathrm{SiC})_{1-}$ ${ }_{x}(\mathrm{AlN})_{\mathrm{x}}$. SiC, AlN and their solid solutions. These structures are of increased adoption in the high performance optical applications. Although AlN substrates have some great characteristics for UV-LED fabrication, it is very difficult to make this material. However, a fast sublimation growth process that deposits $\mathrm{AlN}$ onto $\mathrm{SiC}$ is producing very encouraging results, including incredibly low defect densities.

Layers were produced by fast sublimation of polycrystalline source $(\mathrm{SiC})_{1-\mathrm{x}}(\mathrm{AlN})_{\mathrm{x}}$. So obtained layers were studied by FEI Quanta 200 and Quanta 200 3D Scanning Electron Microscopes and NT-MDT Ntegra Prima Atomic Force Microscope. The result of analysis shows that increasing of the growth temperature up to 2300 


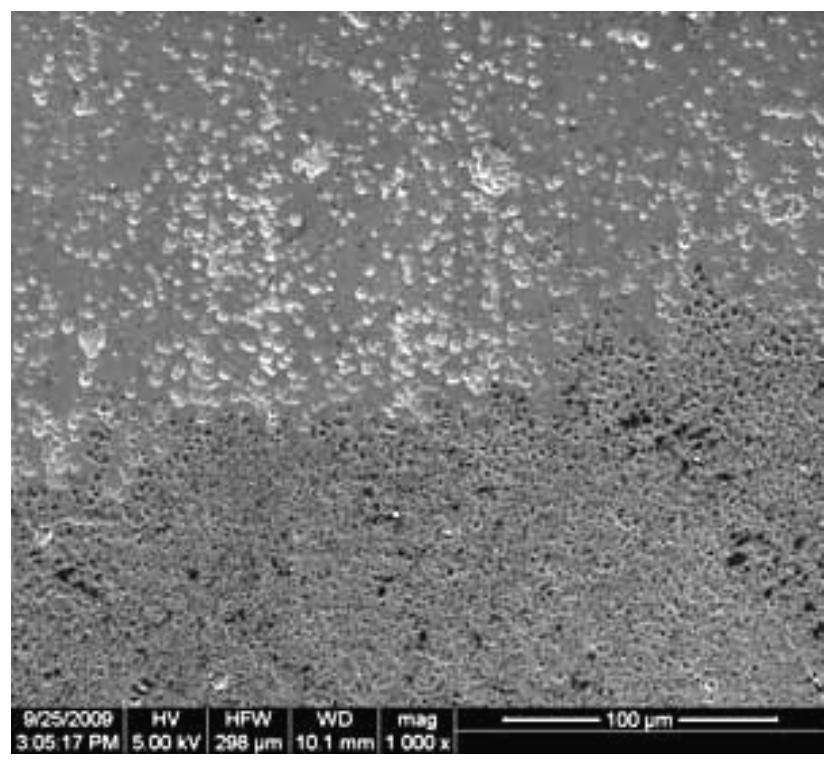

Fig.9. Epitaxial layer of aluminium nitride obtained at $\mathrm{T}=2100 \mathrm{~K}$

\section{Acknowledgements}

This study has been granted by Russian Federal task program "Scientific and research and educational personnel of Innovated Russia for 2009-2013", by GAČR grant 102/11/0995 "Transport of electrons, noise and diagnostics of Schottky and autoemitting cathodes", as well as by MŠMT grant KONTAKT LH 11060 "Local optical and electric characterization of optoelectronic devices with nanometer resolution".

\section{References}

1. J. R. Grandusky, S.B. Gibb, M.C. Mendrik, L.J. Schowalter, Appl. Phys. Exp. 3, 072103 (2010)

2. M. Shatalov, A. Chitnis, P. Yadav, M.F. Hasan, J. Khan, V. Adivarahan, H.P. Maruska, W.H. Sun, M. Asif Khan, Appl. Phys. Letts. 86, 201109 (2005)

3. K. Gunnet, T. Adams, III-Vs Review, 19, 39 (2006)

4. A. G. Bhuiyan, A. Hashimoto, A. Yamamoto, R. Ishigami, J. Cryst. Growth, 212, 379 (2000)

5. H. Morkoc, Handbook of nitride semiconductors and devices, vol. 1, (Wiley-VCH, Weinheim, 2008)

6. Z. An, C.Men, J. Yu, P. K. Chu, C.Lin, J. Appl. Phys., 94, 1934 ( 2003)

7. J.C. Yang, H.G. Na, H.S. Kim, M.A. Kebede, R. Choi, J.K. Jeong, C. Lee and H.W. Kim, Proc. 14th Int. Symposium Ultrafast Phenomena in Semiconductors, 119, 125 (2011)

8. H. Harris, N. Biswas, H. Temkin, and S. Gangopadhyay, M. Strathman, J. Appl. Phys. 90, 5825 (2001)

9. S. I. Vlaskina, K. W. Kim, Y. S. Kim, Y. P. Lee, G. S. Svechnikov, J Korean Phys Soc. 31, 117 (1997)
10. J. S. Johnson, K. Grobsky, D. J. Bray, SPIE Proc., 4771, 243 (2002)

11. N. Komarevskiy, V. Shklover, L. Braginsky, Ch. Hafner, J. Lawson. Opt Exp. 20, 14189 (2012)

12. A. Vonsovici, G.T. Reed, A.G.R. Evans, F. Namavar, SPIE Proc. 3630, 115 (1999)

13. S.I. Vlaskina, V.I. Vlaskin, S.A. Podlasov, V.E. Rodionov, G.S. Svechnikov. Semicond. Phys. Quantum Electron. Optoelectron. 10, 21 (2007)

14. E. Monroy, F. Guillot, S. Leconte, E. Bellet-Amalric, L. Nevou, L. Doyennette, M. Tchernycheva, F.H. Julien, E. Baumann, F. Giorgetta, D. Hofstetter, Le Si Dang, Acta Phys. Pol. A 110, 295 (2006)

15. D.Dallaeva, B. Bilalov, G. Kardashova, S.Eubov, A.Gadjiev, In the World of Sci. Discov., 4, 24 (2010)

16. G.K.Safaraliev, B.A.Bilalov, D.S.Dallaeva, Sh.M. Ramazanov, K.M.Geraev, P.Tománek, SPIE Proc. 8306, 83061K1 (2012)

17. G. Kh. Azhdarova, Z. M. Zeynalov, Z. A. Agamaliyeva, A. I. Kyazimova, Crystallogr. Rep. 55, 716 (2010)

18. M. Matovic, J.C. van Miltenburg, J. Los, J. Cryst. Growth, 275, e211 (2005) 